\title{
A Psychological View of Complex Numbers through Classical and Quantum Computing
}

\author{
Antonio Cassella ${ }^{1}$ \\ ${ }^{1}$ President of Research Autism LLC (FL) and Director of Imerisya (Instituto merideño de investigación de la inteligencia \\ social y del autismo, Mérida, Venezuela).
}

Correspondence: Antonio Cassella, 1270 N. Wickham Rd. 16-613, Melbourne, FL, 32935, USA.

Received: October 11, 2017

doi:10.11114/ijsss.v6i1.2872

\author{
Accepted: December 11, $2017 \quad$ Available online: December 19, 2017 \\ URL: https://doi.org/10.11114/ijsss.v6i1.2872
}

\begin{abstract}
This article explores a psychological view of zero and complex numbers under the embrace of classical with quantum computing. At first, the author broaches classical computing, after-the-fact learning, and the perfect finiteness of the first attention spared in high-functioning autistics. Secondly, he deals with quantum computing, before-the-fact learning, and the less-than-perfect infinity of the second attention impaired in the autistic spectrum before the age of three years. The author emphasizes that quantum computing in the second step agrees with quantum coherence, the angle Greek Pi $(\pi)$ in radians, Euler's Identity $\left(e^{i \pi}+1=0\right)$, and the exploration of schizophrenic interpretations with a probability of existence equivalent to algebraic zero. Thirdly, this article shows that the alliance of classical with quantum computing, or of the first with the second attention, allows the atoned self to reach transcendental zero, quantum decoherence, and a renovated home in the arms of the Third Attention. In turn, the renewal brought by the Third Attention can be linked to the angle twice Greek Pi ( $\tau$, or Tau), the "Tau" Identity $\left(e^{i \tau}-1=0\right)$, the union of real with imaginary numbers in complex numbers, and the proposition by Pythagoras that "all is number."
\end{abstract}

Keywords: Algebraic zero, autism, classical computing, complex numbers, finiteness, infinity, quantum computing, schizophrenia, transcendental zero

\section{Introduction}

At the turn of the $20^{\text {th }}$ century, I explored (Cassella, 1997, 2000, 2002a, 2002b, 2008) the reasons why high-functioning autistics succeed at tests fixed in the repetitive finiteness enclosed in classical computing, spacetime, semantics, and syntax; for example, Proper Self (Povinelli, Landau, and Perilloux, 1996) and Zaitchik's Photo Test (Zaitchik, 1990). I also researched the roots of the failure of autistics in tests fed by quantum computing, hyperspace (Caramazza, 1994), and the embrace of infinity with nothingness in the pragmatics that readjusts semantics and syntax (Padrón,1996); for example, shifts of attention (Courchesne et al., 1994; Johnson, 1994; Landry and Bryson, 2004), the deictic use of personal pronouns (Baron-Cohen, Tager-Flusberg, and Cohen, 1993), and false-belief tasks (Baron-Cohen, Leslie, and Frith, 1985; Baron-Cohen, 1995).

At the beginning of the second decade of the $21^{\text {st }}$ century, the alliance of the principles of classical computing preserved in high-functioning autistics with the principles of quantum computing damaged in the autistic spectrum before the age of three years marked the formal consolidation of my quantitative and qualitative research into the logos psychological heuristic (Cassella, 2011). In the last six years (Cassella, 2013, 2016, 2017a, 2017b, 2017c, 2017d, 2017e, 2017f), I have tried to falsify $\operatorname{logos}($ or $\Lambda$ ) in diverse fields of thought by stressing the universal features and the reciprocal empowerment of three sides of the creative mind:

1. Within the first attention, our autistic facet allows us to seize the recurring luminosity of real numbers, semantics, syntax, and to share known beliefs with other members of the culture we belong to;

2. within the second attention, our curious facet (which autistics cannot fathom) places between parentheses a known belief and goes to the edge of madness in order to seize the darkness of imaginary numbers, discourse pragmatics, and personal pronouns; finally,

3. within the Third Attention, our social facet (impaired in both autism and schizophrenia) allows us to seize the rise of complex numbers, laugh heartily at any hindrance, and devise more adaptive beliefs. 
My latest research (Cassella, 2017g) found that the Third Attention sustains our vein of humanistic creativity and our smiles at puns lodged in the crossing of opposite beliefs. In my view (Cassella, 2016), our Stone-Age ancestors knew that the Third Attention redirects the power of our second attention to place between parentheses the repetitive truths guarded by our autistic first attention. Although our ancestors did not possess our mathematical sophistication, they did not ignore that finite memory in the first attention and infinite imagination in the second attention feed the social power of our Third Attention to renew the self, the other, and the world. Human beings knew, 40000 years ago, that ...

a) the emotional side of our Third Attention animates our sense of humor, shame, and atonement before depression takes over;

b) the cognitive side of our Third Attention allows us to uncover new and better ways to deal with the ambiguities that permeate reality before dementia takes over; and

c) our emotional side and our cognitive side allow us to overcome any challenge under the sun if we recognize in time the social value of their alliance.

One example of the alliance of emotion and cognition in solving social problems is dealing fairly with a suspect. In a fair judgment, jurors:

1. remain silent, while they engage their first attention in listening to the facts placed against a defendant by the prosecutor, and in favor of the defendant by the defense lawyer;

2. speak spontaneously while they engage their second attention and quantum coherence in opposing each other's views and in exploring the pros and cons of the defendant's situation; and,

3. engage their Third Attention and quantum decoherence in arriving at the defendant's innocence or guilt.

In more detail, imagine that a group of jurors are asked to discuss the situation of a drunk defendant who crossed at high speed several intersections marked with a red traffic light, did not slow down before an intersection ruled by a yellow traffic light, and subsequently entered into a collision when he accelerated before an intersection freed by a green traffic light, just when a rival driver disrespected the red light.

The defendant will be found guilty upon the implicit conclusion that his drunkenness had suspended the autistic capacity of his first attention to stop at a red light, the probing capacity of his second attention to deal in context with a yellow light, and the social capacity of his Third Attention to stop before a green light when a competing driver does not stop at a red light. As Heraclitus said in the $6^{\text {th }}$ century BCE (Before the Common Era) about people who lose briefly

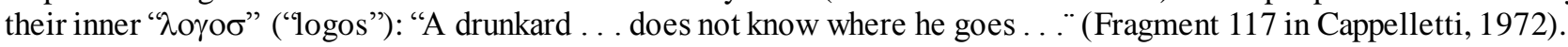

The danger of a collision in a busy intersection stems from the general belief of our first attention that two or more objects cannot share the same space at the same time (within the Principle of Impenetrability); and that no one can be in two places simultaneously (within the Principle of Locality). Opposite to those principles, our second attention believes that two or more objects can share the same space at the same time (the Principle of Coincidence); and that anything in the universe can be in two or more places simultaneously (the Principle of Ubiquity).

Although fair judges and jurors may not realize it, the Third Attention (or the inner logos) of a sober driver may harmonize the principles of Ubiquity and Coincidence in the second attention with the principles of Locality and Impenetrability in the first attention (Cassella, 2017c, 2017g).

This article hypothesizes that the Third Attention of restrained drivers, the merge of real with imaginary numbers in the rise of complex numbers, transcendental zero, the merge of semantics, syntax, and pragmatics in spontaneous discourse, and the merge of knowledge and imagination in overcoming any challenge obey all the distributed hierarchy attached to the Third Attention.

\section{Methods}

In the background, I apply the logos heuristic to highlight the ambiguity that surrounds the nature of zero, of Greek Pi, and of Euler's Identity.

In the subsequent discussion, I lean on the first attention, on the second attention, and on their reciprocal empowerment within the Third Attention to arrive at the transcendental nature of zero, the "Tau" Identity, and at a psychological view of algebraic and transcendental numbers. That view may lead to a better self, a better other, and a better world.

\section{Background}

\subsection{The Reckless Betrayal that Ended the Life of Joseph Smith}

In the $5^{\text {th }}$ century BCE, the prophet Zechariah $(11: 07 ; 11: 10 ; 11: 14)$ wrote (Katznelson, 1991) that our recklessness would compel God to break first his staff No'am (humans' second attention and the stone Urim kept in the Ark of the 
Covenant), and later, his staff Hovalim (humans' first attention and the stone Thummim, also guarded in the vanished Ark). Moreover, Zechariah asserted that the loss of the quantum staff No'am and of the classical staff Hovalim (or the loss of the crystals Urim and Thummim) would bring the premature death of $2 / 3$ of people on Earth $(13: 07 ; 13: 08)$. If we continue to cause and to simultaneously deny global warming, our betrayal of the universal promise of creativity and progress will simultaneously prove the truth of Zechariah's warning and hit badly our great grandchildren at the turn of the $21^{\text {st }}$ century. Nanoparticles freed by diesel-engine filters, for example, are toxic to the lungs of the young. Yet the malice that hides behind ignorance, arrogance, ambition, and egoism is oblivious to the sufferings of future generations.

Similarly, the malicious use of the second attention in a few characters in love with personal power led in the $19^{\text {th }}$ century to the reckless betrayal that caused the premature death of the prophet Joseph Smith. Ironically, that betrayal also led to the completion of his dreams. Before Smith's death, the Angel Moroni had loaned him the two crystals Thummim and Urim, the two staffs Hovalim and No'am, classical and quantum computing, or the first and the second attention). The combination of the two crystals in the mind of Joseph Smith helped him translate the teachings enclosed in the ancient Book of Mormon. ${ }^{1}$

Smith's mystical perception of the union of the Thummim and Urim crystals, or of the staffs Hovalim and No'am, as the place in which God resides (D\&A 130:6/11) suggests that the Third Attention of Zechariah foresaw that our descendants will overcome the destruction linked to impending global warming if we value now three miracles:

1. The miracle of memory after the facts, of the repetitive meaning of words, and of our dealing with real numbers, firmed up by the Thummim of the first attention spared in high-functioning autistics;

2. the miracle of learning before the facts, of facing irony, and of playing with imaginary numbers, firmed up by the Urim of the second attention impaired in the autistic spectrum; and

3. the miracle of the renewal linked to the distributed organization of complex numbers, of creative discourse, and of the union of the Thummim and Urim crystals in the Third Attention hindered in autism and schizophrenia.

\subsection{The Impact of Global Warming at the Turn of the 21st Century}

Zechariah's prophecy of a dreadful scenario agrees with a situation of climate change in which the content of carbon dioxide $\left(\mathrm{CO}_{2}\right)$ in the atmosphere will reach and surpass $1350 \mathrm{ppm}$ (parts per million) at the turn of the $21^{\text {s }}$ century (Cassella, 2017a, 2017c). The content of $\mathrm{CO}_{2}$ in the atmosphere was about $405 \mathrm{ppm}$ by the end of 2017; and $260 \mathrm{ppm}$, before the Industrial Revolution. The $145 \mathrm{ppm}$ rise of the atmospheric concentration of $\mathrm{CO}_{2}$ in the last three centuries owes to the fact that the advances of science, mathematics, and technology have fostered an increase of ten times in the consumption of energy per capita and in the number of living people on Earth.

Unfortunately, today's situation can worsen. If the average per-capita consumption increased from 12 barrels of equivalent oil (BEO) per year (B.P., 2016) to 25 BEO per year at the turn of the $21^{\text {st }}$ century (Cassella, 2017a), in a collusion with an increase to 11 billion people on Earth, Zechariah's annoying warning will become real.

In line with Zechariah's implicit aim of waking us up before the world death rate surpassed by far the birth rate, Mesoamerican legends propose that humanity will reach a new horizon of progress if a few farsighted leaders and their wily followers understand the esoteric meaning of the return of the Mesoamerican demigod Quetzalcoatl. Under that acknowledgement, we will reduce the quantity of greenhouse gases thrown every year into the atmosphere and even remove the obnoxious gases released since the onset of the Industrial Revolution. Holding into the ingenuity, wittiness, and social warmth that autistics cannot handle will help us hand out a clean atmosphere to our great grandchildren!

\subsection{The Salvation Imparted by the Return of Quetzalcoatl}

Mesoamerican legends entail the hope that an undaunted spirit will help us keep our first attention, while changing the diabolical ascent of our second attention into the saintly descent of the Third Attention (Figure 1).

That heroic feat can be attributed to the return of "Quetzal-coatl" ("Feathered Serpent," in the Nahuatl language of the Aztecs), the demigod venerated with an unknown name in Teotihuacan until the $7^{\text {th }}$ century CE (Common Era), when that Mesoamerican city was abandoned by laborers pressed by a lengthy lack of food and clean water. Unlike ancient Teotihuacans, we do not enjoy the option of moving to better grounds. Our only path to salvation lies in getting the metaphorical meaning of the going journey (top of Figure 1) and of the returning journey (bottom of Figure 1) of Quetzalcoatl.

Alegend goes that, in the $13^{\text {th }}$ century CE, a few Toltecs sages told a few Aztec warriors who arrived at Teotihuacan that a daring demigod of theirs, Quetzalcoatl, had left behind the rigidity of the spacetime attached to a serpent-coatl. That heroic explorer pursued the maddening flexibility of a quetzal-bird by crossing the imaginary hyperspace (Caramazza,

\footnotetext{
${ }^{1}$ Also the University of Yale combines in its emblem the symbolic Urim and Thummim.
} 
1994) that lies between the Earth and Venus (quantum coherence and the Morning Star at the top of Figure 1). Beyond legend, the quantum idea behind the exploratory thrust of Quetzalcoatl as a plumed serpent (2) unites the earthly rigidity (1) of autistics (the serpent at the lower right in Figure 1) and the empty flexibility (-1) of schizophrenics (the bird at the upper left of Figure 1).

The Toltec sages told the intruding Aztec warriors that Quetzalcoatl would return from Venus to the Earth someday, carrying with her the secret about nature's Nature (Figure 1, quantum decoherence). Her return would guide global civilization into a new wave of progress. Likewise, Don Juan, the spiritual guide of the anthropologist Carlos Castaneda, implied that, at a certain point of human history, the Tonal (1) of the first attention (Castaneda, 1972) and the Nagual (2) of the second attention (Castaneda, 1972) will empower each other (3) under the wings of the decoherence fed by the Eagle of the Third Attention (Castaneda, 1991), a sign of the return of Quetzalcoatl (at the bottom left of Figure 1).

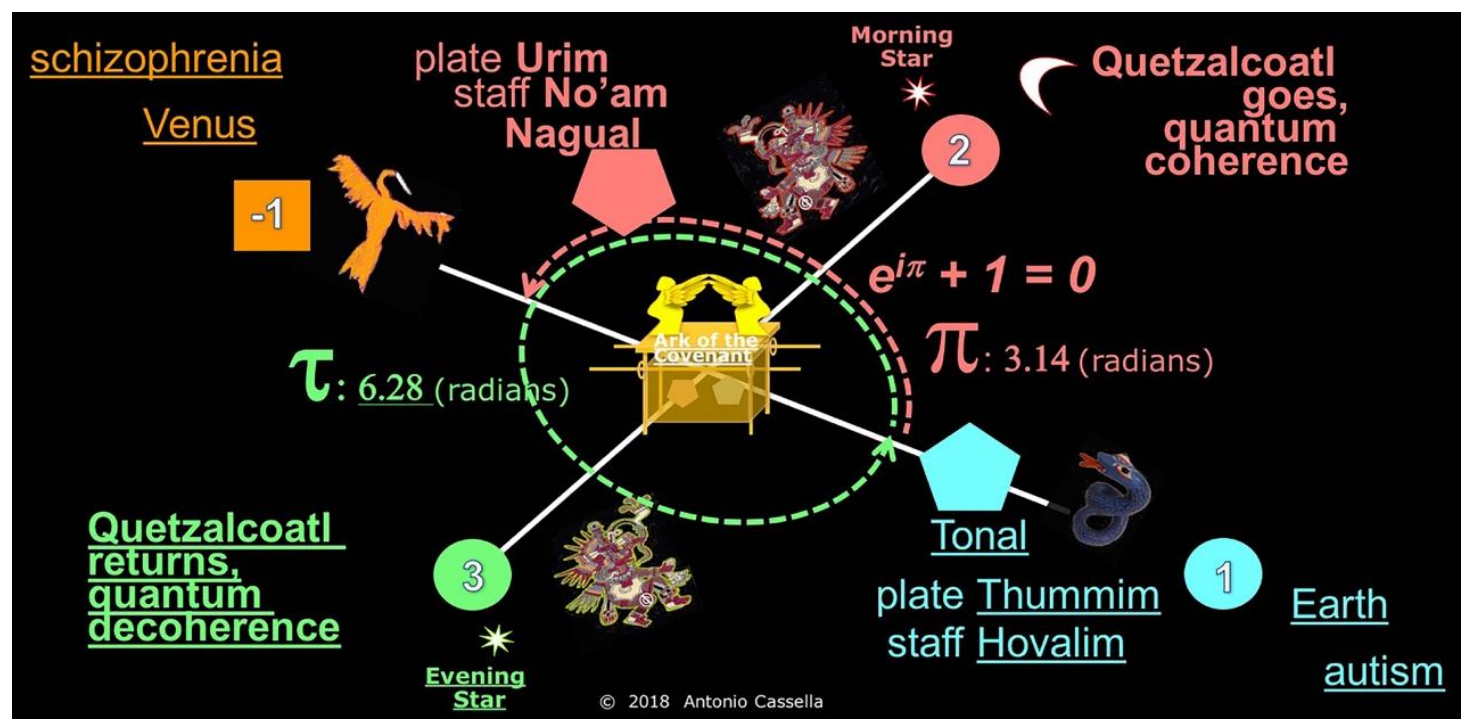

Figure 1. The going and the returning journeys of Quetzalcoatl

The Aztecs who invaded the high Valley of Mexico in the $13^{\text {th }}$ century CE can be compared with the unadventurous serpent-Tonal trapped in earthly spacetime (step 1, at the right of Figure 1). The autistic facet of the Aztecs was blind to the going journey (step 2, the angle Pi, and the Morning Star) of the audacious bird-serpent-Nagual. Neither did they grasp the possibility that the belief in the Third Attention of a saintly Quetzalcoatl would convince her to return someday (step 3 and the angle Tau), in the wake of the Evening Star, to save all humans. In overwhelming the classical immaturity of the Aztecs, the quantum malice of the Spanish "Conquistador" Hernán Cortés matches the treason that has been destroying the biota and the atmosphere of the Earth in the last 300 years. Today, the pettiness of most leaders and of their blind supporters shows that most people continue ignoring the meaning of the return of Quetzalcoatl.

The return of Quetzalcoatl from Venus, the return of the Chinese Laozi from the Taklamakan desert, of the Hindu Rama after freeing his beautiful Sita from the seduction endeavored by the diabolical Ravana, of any Buddhist Bodhisattva who seeks to enlighten the blind, of Christ from his transfiguration at the top of Mount Tabor, of Muhammad from the Farthest Mosque, and of the angel Moroni from quantum hyperspace are all metaphors of the social landing of Quetzalcoatl and of our Third Attention into a renewed Earth. If we leave behind the selfish behavior that has hijacked the capacity for quantum computing of our second attention, Quetzalcoatl will return to a renewed Earth with the secret of the Third Attention.

Beyond science, metaphorical knowledge in any field of thought may foster that miracle. Because autistics and our classical autistic facet cannot fathom metaphors, exploring the metaphorical nature of zero and complex numbers may help our artistic facet capture, face in time, and overcome crucial social and climate challenges. That doing conveys the alliance of the exploratory influence of the semicircle marked by the ambiguity of Greek Pi with the resolve of the circle defined by Greek Tau (Figure 1). Definitely, we should lean on the transcendence of Greek Pi and Tau to cut global warming and terrorism now, instead of tossing unsolvable challenges on our great grandchildren.

\subsection{The Ambiguity Enclosed in the Transcendence of Greek Pi, Greek Tau, and Euler's Number}

March 14 of every year is considered Pi Day all over the world (the name "Pi" is pronounced as the word "pie"). Pi Day, or the recognition of the first three digits $(3,1$, and 4 ) in the mathematical constant $\pi$ (Greek Pi), or 3.14 followed by an infinite number of digits, reveals our familiarity with the presence of $\pi$ in our interpretations of reality. We know that $\pi$ 
represents the relationship between a circumference and its diameter. Some of us, however, would value better a doubling sister constant- $\tau$ (Greek Tau, or 6.28 followed by an infinite number of digits). Tau reflects the constant relationship between a circumference and its radius, a fact that pushes the number 2 out of most of the equations faced by graduate students in scientific branches.

As I suggest in Figure 1, when we use radians to seize an angle, Greek Pi points at a semicircle (the upper part of Figure 1). By contrast, when we use Tau, the semicircle becomes a circle (the central part of Figure 1). Beyond the controversy between $\pi$ and $\tau$, we ignore the psychological nature of the semicircle around Pi and of the circle behind Tau.

A similar dearth of knowledge pervades our assessment of the nature of Euler's number, $e=2.71 \ldots$ followed by an infinite number of digits. Euler's number offers many advantages, for example, $e$ is taken as the foundation of natural logarithms and is used in calculus because the exponential function $e^{x}$, in which infinity embraces nothingness, is its own derivative and antiderivative.

When the exponent in $e^{x}$ becomes a complex number by multiplying it by the imaginary unit " $i$," the use of polar notation allows us to arrive at the equation $e^{i x}=\cos x+i \sin x$, which is called "Euler's formula." A special case of Euler's formula is Euler's Identity, or $e^{i \pi}+1=0$ (Figure 1, quantum coherence). Richard Feynman, a Nobel Prize in Physics, pointed at the beauty of Euler's Identity, which relates Euler's number $(e)$ with Greek Pi, the imaginary unit $i$, the number 1, and zero. However, no one has explained yet the psychological meaning of Euler's Identity and of zero in it.

Greek Pi and Euler's number are transcendental, which means that they are not algebraic, the case of rational numbers expressed as the quotient of two integers in which the denominator is not zero. Beyond the complexity of the standard definition of algebraic numbers, I appreciate the fact that they are countable, whereas transcendental numbers (that is, almost all real, imaginary, irrational, and complex numbers) cannot be counted.

Unlike uncountable transcendental numbers, algebraic-minded bankers like to count. Their love for constructive interest rates compels bankers to balance above and beyond nothingness the loans they give to and the loans they receive from their customers. The ambiguity around nothingness, however, challenges bankers, our bank accounts, and our courage with an unfathomable double nature.

\subsection{The Uncertainty that Presses the Nature of Zero}

No one knows if zero is transcendental, algebraic, or both. Possibly, the untamed nature of zero derives from its strange relationship with nothingness, unity, and infinity. For example, dividing one dollar into four parts, results in a quarter; dividing one dollar into 10 parts, results into a dime, and dividing it into 100 parts results into a penny. Obviously, dividing the number 1 into infinite parts results in the number zero. That fact denotes the strange relationship between visible unity (1), unseizable infinity $(\propto)$, and invisible nothingness ( 0$)$.

The relationship $1 / \propto=0$ evoked the wonder of many scholastic philosophers in the Middle Ages. Duns Scotus, for example, wondered in the $13^{\text {th }}$ century about how many angels can dance on the top of a pin (Copplestone, 1962b). If the number one (1) represents the pin, zero would represent its invisible top, and infinity could be applied to the number of angels. Indeed, an infinite number of angels could dance on the nothingness that makes the top of a pin if they shared the same space at the same time (the Principle of Coincidence in logos). Once we accept the possibility that an infinite number of angels may dance in the nothingness that pervades the top of a pin, we may also accept the possibility that a same angel can dance in two places, or in infinite places, simultaneously (the Principle of Ubiquity in logos).

Was Duns Scotus a dunce? Or did he suggest to us metaphorically that the relationship $1 / \propto=0$ between measurable reality (the pin, or the autistic facet of our first attention), infinity (the angels, or graceful ambiguity in the second attention), and transcendental nothingness (the top of a pin, or the Third Attention) makes all numbers, the human mind, the universe, fair teachings, the union of the crystals Urim and Thummim, and the place in which God resides?

The following discussion aims not at reviewing known concepts worked out by others in the complexity of pure mathematics, which I do not master. I deal here with the psychological nature of numbers as a means to stop global warming, align our disposition and behavior toward global cooling in the next 7000 years, and recover the social values that permeate all Sacred Texts, all masterpieces of the arts, and even the complexity of pure mathematics.

I believe that if we allied modern mathematical constructs with the vision about social values that we lost and that Neanderthal and African humans associated to the union of infinity and nothingness in any crossing (Cassella, 2016), we could re-direct global warming and terrorism into a new horizon of progress (Cassella, 2017c).

\section{Discussion}

\subsection{The Meeting of Infinity and Nothingness in any Crossing}

Duns Scotus never read the poem De rerum natura (Over the nature of things) written by the Roman Titus Lucretius 
Carus in the $1^{\text {s }}$ century BCE (Greenblatt, 2012). Still, Scotus aligned his scholastic philosophy with the atomistic crossing of infinity and nothingness in the union of matter (1) and void (0) that Lucretius had taken from the writings of the Greek philosopher Epicurus in the $3^{\text {rd }}$ century BCE. That was not the case of the mathematician Euclid, whose Euclidean geometry (Figure 2) tried in the same century to avoid altogether the infinite ambiguity unleashed by Epicurus and by the pre-Socratic philosophy of Heraclitus The Obscure, which Lucretius misconstrued and criticized.

Unlike the atomistic crossings appreciated by Epicurus, Euclid's geometrical approach considered the situation of parallel straight lines that never cross each other in following the same direction. Given a particular straight line (for example, the one that passes through algebraic zero in the center of Figure 2), we may think of an infinite number of parallel lines at its left and at its right (Figure 2). All those parallel lines become a metaphor for the set of positive $(1,2$, $3, \ldots)$ and negative $(-1,-2,-3, \ldots)$ integers. Altogether, the positive and negative integers make the set that modern mathematics denotes by a boldface Z, the initial of "Zahlen," the German word for numbers.

If we add to the set $Z$ the infinite number of parallel lines that can be traced between any two positive or negative integers, for example, the parallel lines that represent the quotient of two integers, the set $Z$ can be enlarged into the set $\mathrm{Q}$ of rational numbers (for example, the number $1 / 2$ in Figure 2). The letter $\mathrm{Q}$, chosen by modern mathematicians, points at the initial of the Italian word "quoziente" ("quotient"). With its expansion after a decimal separator, the decimal notation helps us represent rational and irrational numbers. Actually, we know that there are "crazy" or "irrational" lines whose decimal part rejects repetition, while courting an infinite extension into nothingness (i.e., the square root of 2 in Figure 2).

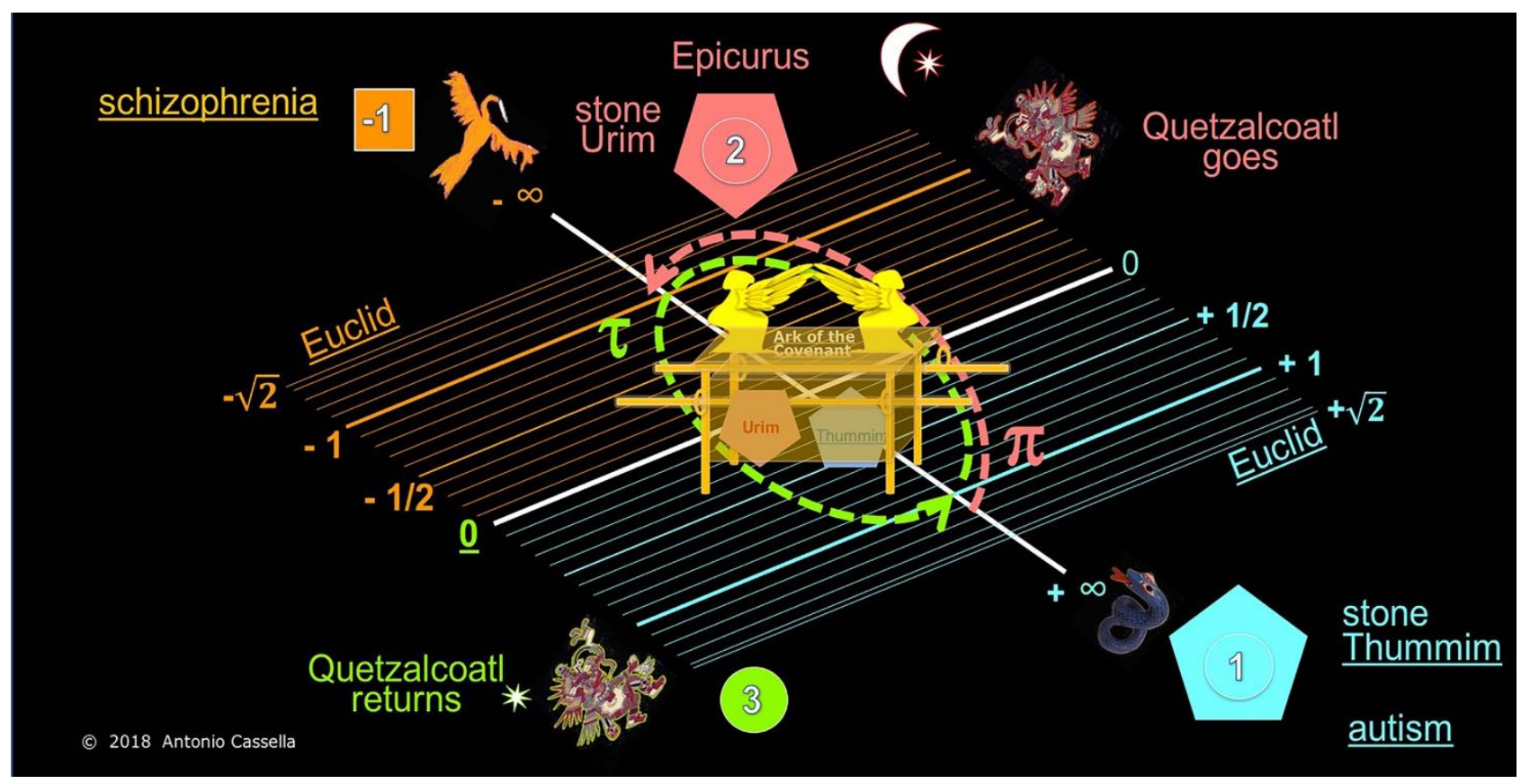

Figure 2. The alliance (3) of crossing straight lines (the red stone Urim) (2) in Epicurus with parallel straight lines (the blue stone Thummim) in Euclid (1)

The geometrical view of the set $\mathrm{Z}$ included in the set $\mathrm{Q}$, lodged in its turn in the wider set of the real numbers $\mathrm{R}$, includes the number zero. Zero may be linked to the initial straight line in Figure 2. However, the mysterious nature of zero can be understood better by crossing two or more straight lines (the center of the two axes shown in Figure 2). As Figure 2 shows, any crossing evokes the meeting of infinity with nothingness in invisible atoms and in the scholastic question about how many angels can dance on the top of a pin. Because autistics and the autistic side of the normal mind cannot handle the embrace of infinity with nothingness that haunts zero, it may be worth exploring the metaphorical meaning of any crossing; for example, in the Christian Cross.

\subsection{The Meeting of Infinity and Nothingness in the Christian Cross}

Galileo's condemnation in the $17^{\text {th }}$ century might respond to the fact that the Jesuit-ruled "Collegio Romano" in Rome never liked the atomistic implications of the crossing of straight lines studied by Duns Scotus in the $13^{\text {th }}$ century (Cassella, 2017a), as referenced at the center of Figures 1 and 2. Pope John Paul II beatified Duns Scotus in 1993. His eventual Sainthood within transcendental zero (in green, at the left of Figure 2), then, may precede the end of the world attached to algebraic zero (in blue, at the right of Figure 2). 
On the one hand, the dimensionless point at the center of any crossing of straight lines (i.e., in the Christian Cross shown in Figure 3) may point to algebraic zero. On the other hand, that nothingness also hides the transcendental infinite (Quantum Entanglement and the Principle of Ubiquity) that exists simultaneously in two different lifelines, the mark of infinite speed, of any joke (Köestler, 1964), and of the going voyage of Quetzalcoatl. In the same fashion, two different points, which belong to two different straight lines, share the same space at the same time in the center of any intersection (at the center of Figures 2 and 3), the mark of nothingness, of quantum superposition, of transcendental zero, and of the Principle of Coincidence that introduces the return of Quetzalcoatl (shown at the left in Figure 2 and at the bottom of Figure 3).

About 100 years before the condemnation of Galileo, the rebellious Martin Luther advanced a miraculous theological view, which valued the heretical concepts of the Omnipresence of Christ in the universe (the Principle of Ubiquity) and of the Consubstantiation of the host and Christ in the Eucharist (the Principle of Coincidence). However, Father Suarez, a most respected Jesuit theologian, remarked immediately that since two substances cannot share the same space at the same time (the Principle of Impenetrability), the Lutheran concept of Consubstantiation would seem repulsive to any person gifted with reason (Cassella, 2017a). The position of Father Suárez suggests that the rigid followers of the principles of Impenetrability and Locality in invariant and precise knowledge cannot grasp the metaphorical crossing of infinity with nothingness at the center of the Sign of the Cross; and at the center of the Cross that stood at the top of Mount Golgotha (Figure 3). Recall now that positive slope becomes zero before changing into the negative slope that descends any mountain.

In Calculus, the top of a hill in which uphill changes into downhill (the bottom of Figure 3) can be compared with the derivative of a function. Differentiation, or the derivative of a position, could be linked to the voyage of Quetzalc oatl to Venus, within quantum coherence and the decreasing light of the Morning Star. In turn, integration, or the antiderivative of the derivative, could be connected to quantum decoherence, or the return of Quetzalcoatl from Venus, in the wake of the increasing luminosity of the Evening Star. Moreover, in view of the fact that the top of a pin cannot be seen, the act of reaching the top of a hill, in which positive slope becomes zero (Figure 3), can be connected to the concept of infinitesimal, to the fundamental theorem of calculus, and to quantum superposition in the beginning of the return of Quetzalcoatl (the light green transcendental zero placed at the left and at the bottom in Figure 3),

All these concepts can be summarized in the symbolic vision (Figure 3) of a cross planted on the top of a mountain. As with Euclid's initial straight line, located in the position of algebraic/transcendental zero within the set "Z" of integers (Figure 2), Jesus was crucified on the top of Mount Golgotha between a bad thief at his left (Gestas and all the negative integers; Figure 3) and a good thief at his right (Dimas and all the positive integers; also Figure 3).

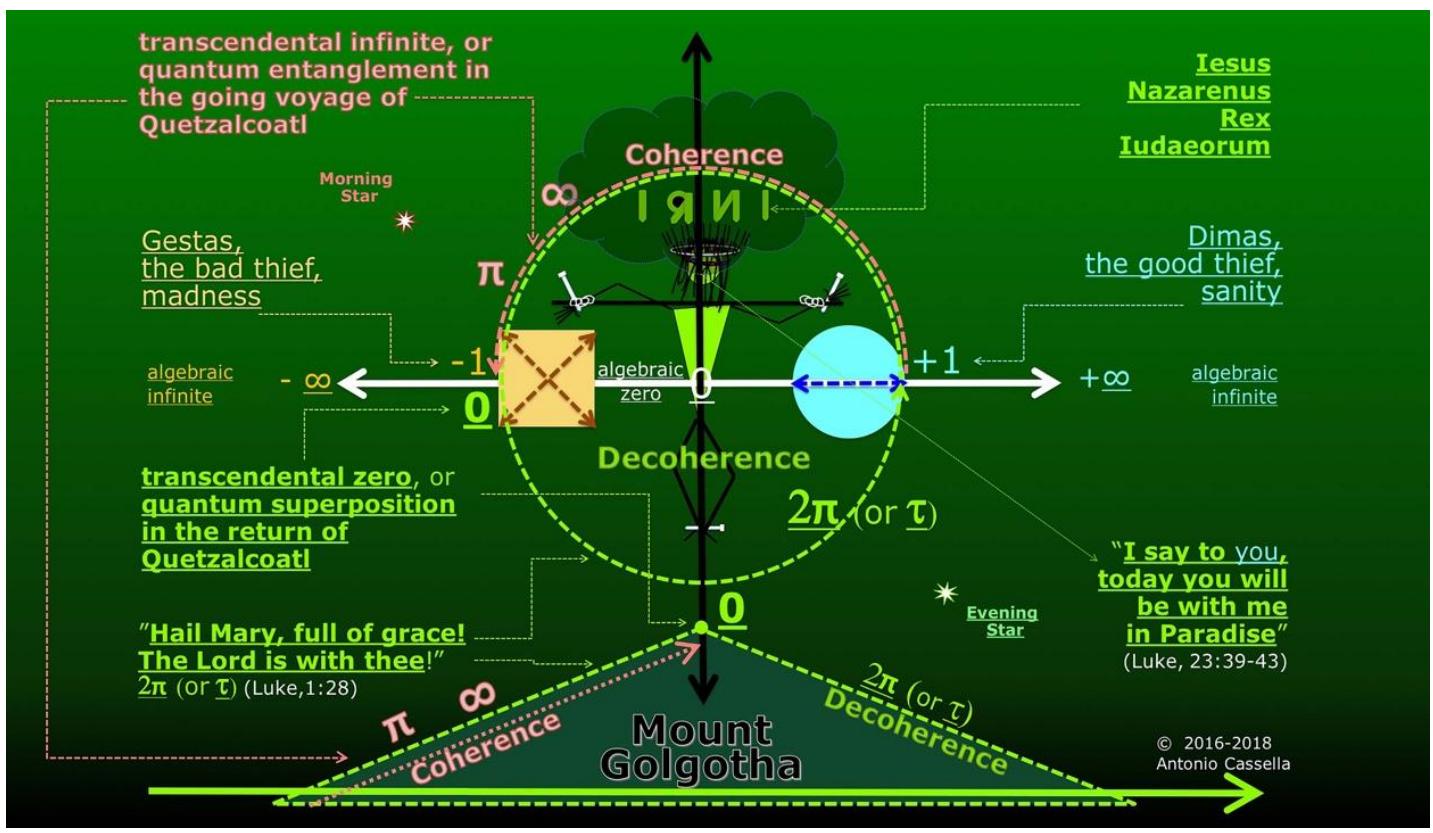

Figure 3. The meeting in the Christian Cross of the circle of sanity, the square of insanity, infinity in quantum coherence, and nothingness in quantum decoherence

Dimas and the circle may be considered a metaphor for the autistic side of the mind, where as Gestas and the square 
becomes a metaphor for the schizophrenic side of the mind. In the same way that the naughtiness of Gestas (-1 and all the negative numbers) cannot seize the goodness of Dimas ( +1 and all the positive numbers), the assumption can be made that, in the mind of graceless men or women, the square cannot fathom the circle.

\subsection{The Four Aspects of Leonardo da Vinci's Vitruvian Man}

Most art historians doubt that Leonardo da Vinci understood that the circle cannot be squared with a compass and a straightedge. The making of Leonardo's Vitruvian Man (Figure 4), however, leads to the hypothesis (Figure 5) that da Vinci knew that gracious human beings can reconcile the square with the circle in their minds.

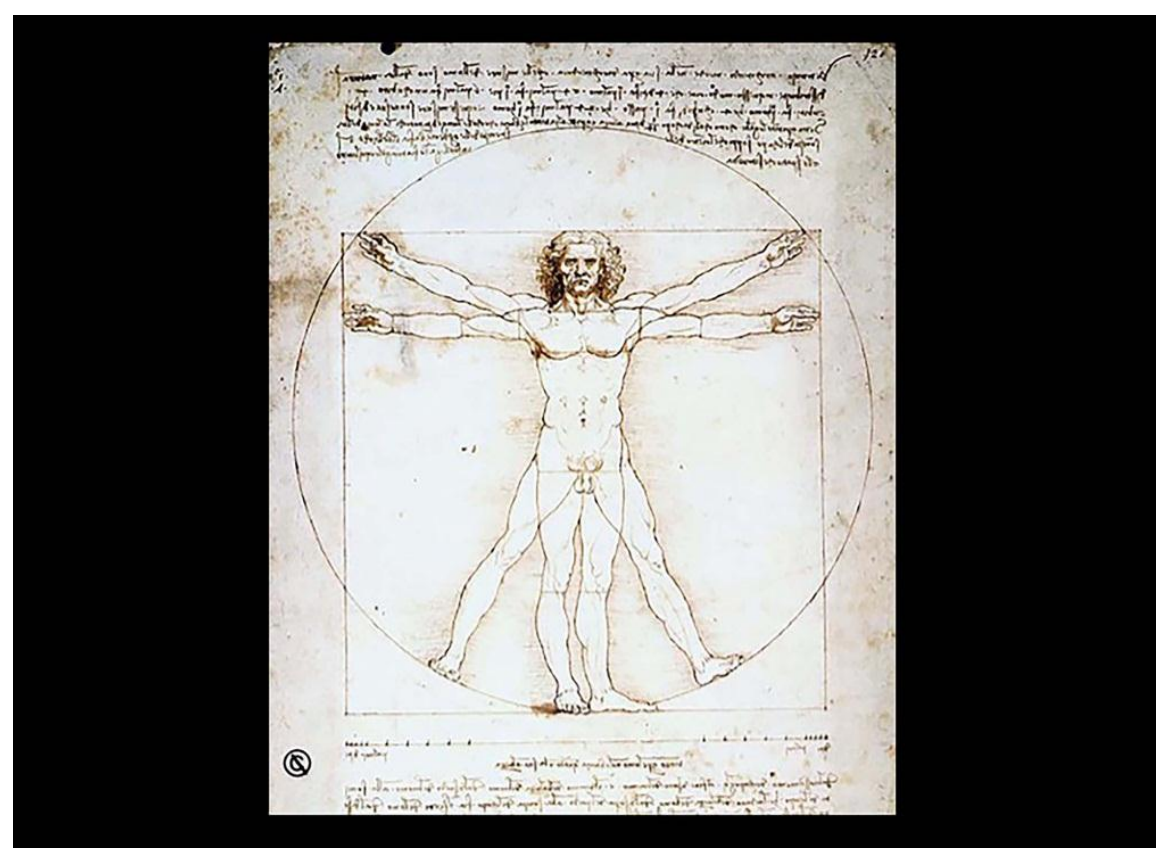

Figure 4. Bridging the difference between the square and the circle in the Vitruvian Man

Leonardo da Vinci interpreted the work De Architectura of the Roman architect and military engineer Vitruvius through the belief that the circle and the square of his Vitruvian Man could not share the same center (Figure 4).

That quantum interpretation hides the four aspects of the human mind shown in Figure 5.

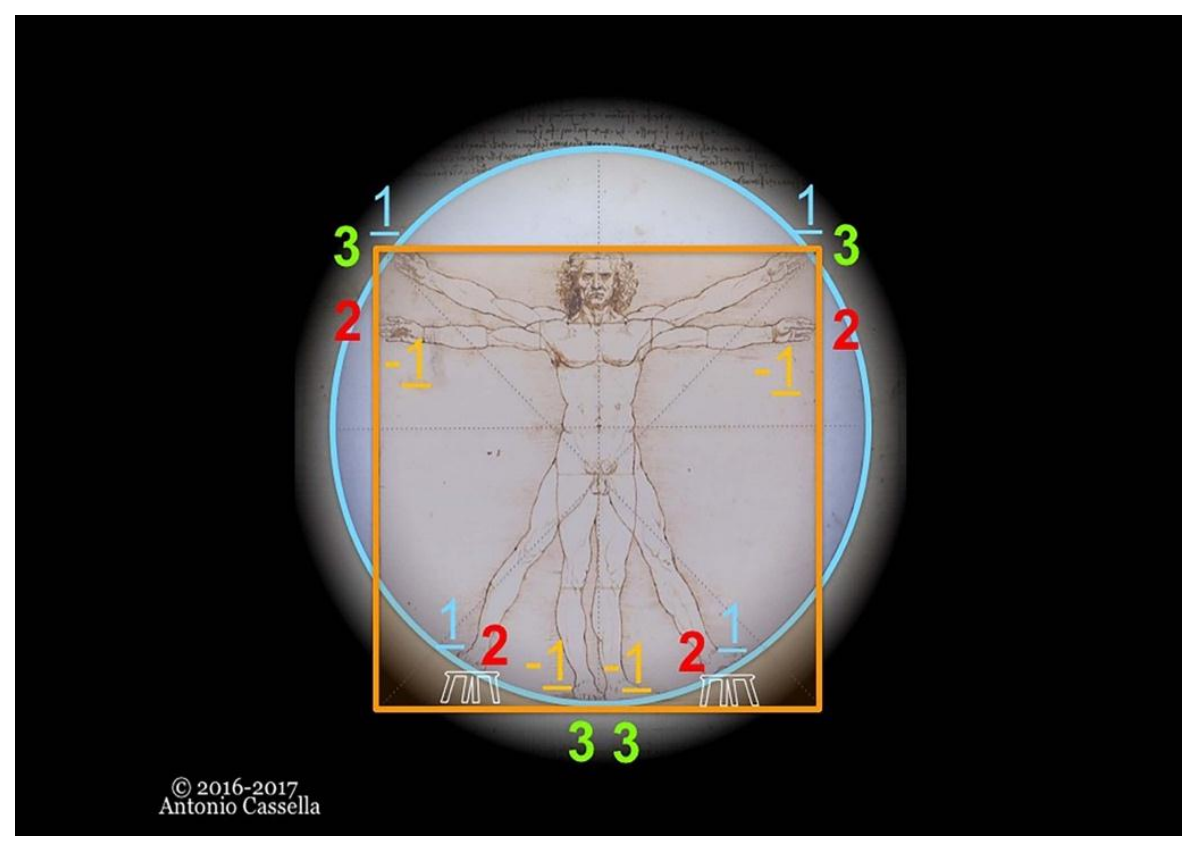

Figure 5. The "four" aspect and the "eight" limbs of Leonardo's Vitruvian Man 
If we stand on two benches and raise our hands at the level of our hair, in the position of the four ones (1), the "X" made by our hands and feet on the circle becomes a metaphor for positive integers, the autistic side of the human mind, and the first attention. The implication here is that the first attention (Dimas) makes the starting point and the ending point (Paradise) of any undertaking.

If we lower our hands in the position shown by the upper twos (2), our hands will touch the lateral sides of the square of lunacy. At the same time, our feet will continue stepping on the circle of sanity in the position shown by the lower twos (2). That position becomes a metaphor for the "mountain" of quantum coherence, for example, the mount (Golgotha) (Figure 3) that held the original Christian Cross.

The mountain of the twos points at the infinite speed of quantum coherence, at the going Quetzalcoatl, at the Devil that tempts jurors with the pros and cons of mutually exclusive alternatives, and at the benefit of doubt that Jes us lent to the sweet words of the atoned Dimas and to the sour words of the unregretful Gestas.

If we lower our feet in the position shown by the negative ones (-1) in Figure 5, we lie totally within the square of madness inherent in Gestas, the bad thief. If we do not abandon our hatred, arrogance, and the attachment to our ego, we will die in the hell of that maddening facet, or the cursed "cross" made by the four "-1" placed at the end of the going voyage of Quetzalcoatl in the second attention.

Fortunately, in the four negative ones, our feet also join the lower threes of the Third Attention, while our arms and hands may rise again in touching the upper threes of the Third Attention. Within the four threes that make the "Eagle" of the Third Attention, we square the circle in our minds, since we touch simultaneously the circle and the square. The power of the Third Attention and of the returning voyage of Quetzalcoatl, shown in the lower part of Figure 3 and in the threes of Figure 5, may lead us to unite the firmness of real numbers with the mystery of imaginary numbers in the creative arrival of complex numbers and another metaphorical manner of squaring the circle.

In explaining better the latter point, I will deal first with the Cartesian plane invented by the French philosopher Descartes (Figure 4).

\subsection{The Rise of Imaginary Numbers beyond Real Numbers}

On the Cartesian plane shown in Figure 6, a circle with radius $=1$ and center in the origin is represented by the equation $x^{2}+y^{2}=1$. Possibly, Descartes discovered the existence of imaginary numbers by exploring what happens if the radius of the circle shown in Figure 6 passed from unity to nothingness, or from 1 to 0.

In my view, the new equation of the circle with radius zero would be $x^{2}+y^{2}=0$. Solving the equation for $y$ would lead us to its two roots, $+x \sqrt{-1}$ and $-x \sqrt{-1}$.

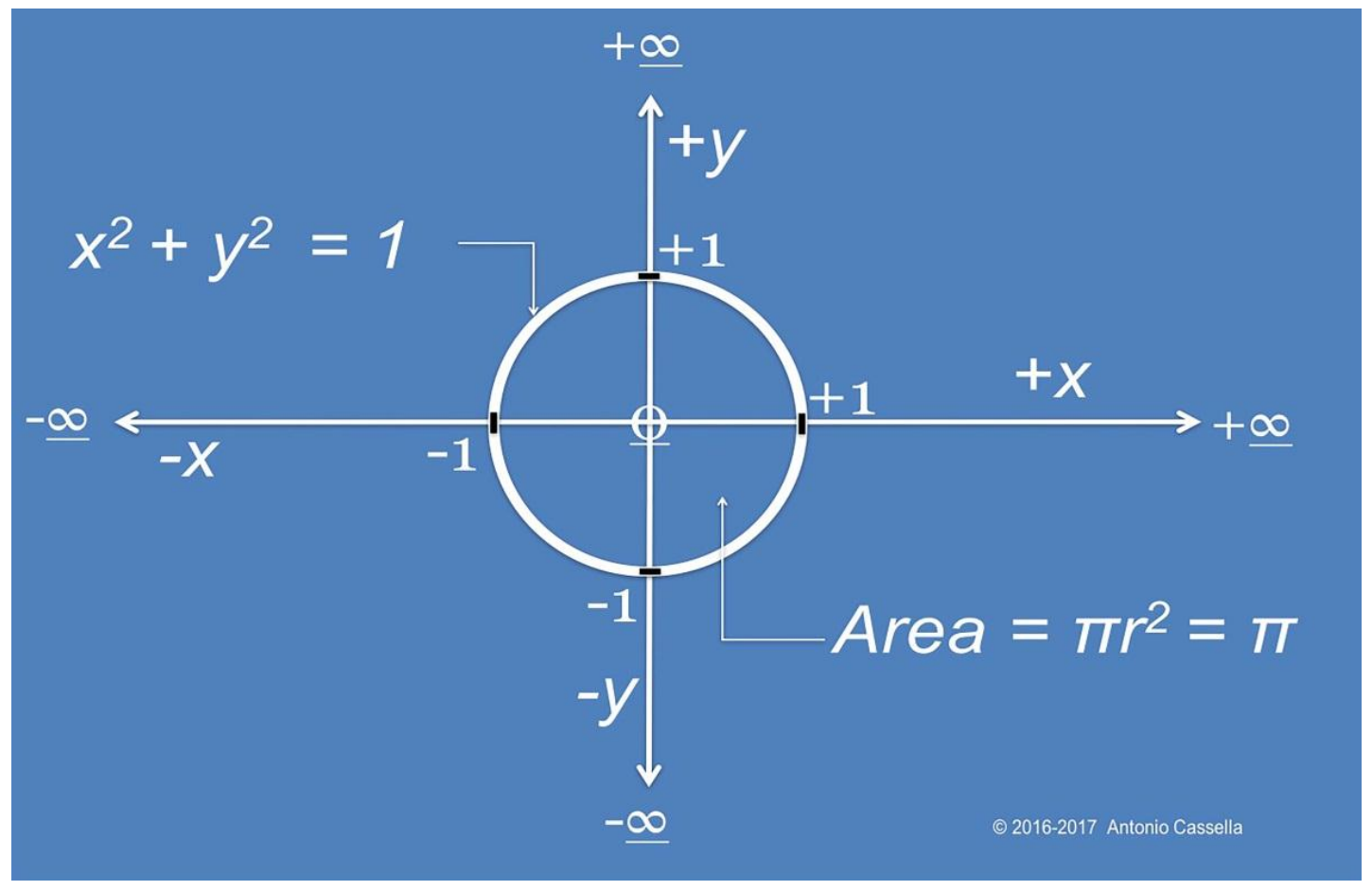

Figure 6. A view of a unitary circle in the Cartesian plane 
I am sure that Descartes or someone else already did long ago what was just done, after recalling the basics of my high-school algebra. Descartes found that the two roots of the equation of a circle with radius zero in the Cartesian plane are meaningless, since the square root of -1 , and of any negative number for that matter, does not exist in visible reality. Descartes wrote that the square root of -1 could be taken as an imaginary unit (i), with no real meaning. Yet its meaning can be explained through the complex plane. By just invoking the features of the complex plane shown in Figure 7, I am not yet doing anything new in mathematics.

I create something new only when I relate the features of the complex plane to the three modes of attention that make the logos psychological heuristic. I begin my analysis by reinforcing the hypothesis, introduced implicitly by Pythagoras, that any mathematical construct responds to the classical/quantum, distributed organization of the human mind and of any system in the universe. I mean: the first attention spared in high-functioning autism, placed between parentheses by the second attention impaired in ASD, which is placed between parentheses by the Third Attention.

\subsection{The Rise of Complex Numbers beyond Imaginary and Real Numbers}

The two roots of the equation of a circle with zero radius in the Cartesian plane sustain the vertical and imaginary axis of the complex plane shown in Figure 7. Known mathematics establishes that the horizontal axis of the complex plane will represent real numbers. Having 1) a horizontal axis that picks up real numbers (under the power of the first attention) and 2) a vertical axis that picks up imaginary numbers (under the power of the second attention) allows 3) representing any complex number in the universe (under the power of the Third Attention).

Current mathematical conventions posit that any complex number can be represented by the addition of a real part (measured in the horizontal "a" axis) with an imaginary part (measured in the "ib" axis). If a small " $z$ " were taken to denote a complex number, its value would be $\underline{z}=\underline{a}+\boldsymbol{i b}$.

What is new here is the hypothesis that any complex number is arrived at by combining the first with the second attention, or the principles of classical with the principles of quantum computing. That hypothesis implies that the real numbers plotted in the horizontal axis will obey the principles of Impenetrability and Locality; the imaginary numbers plotted in the vertical axis will obey the principles of Ubiquity and Coincidence; and the rest of complex numbers will obey simultaneously both sets of principles - in the manner of the sane driver that stops at a green light to save a life.

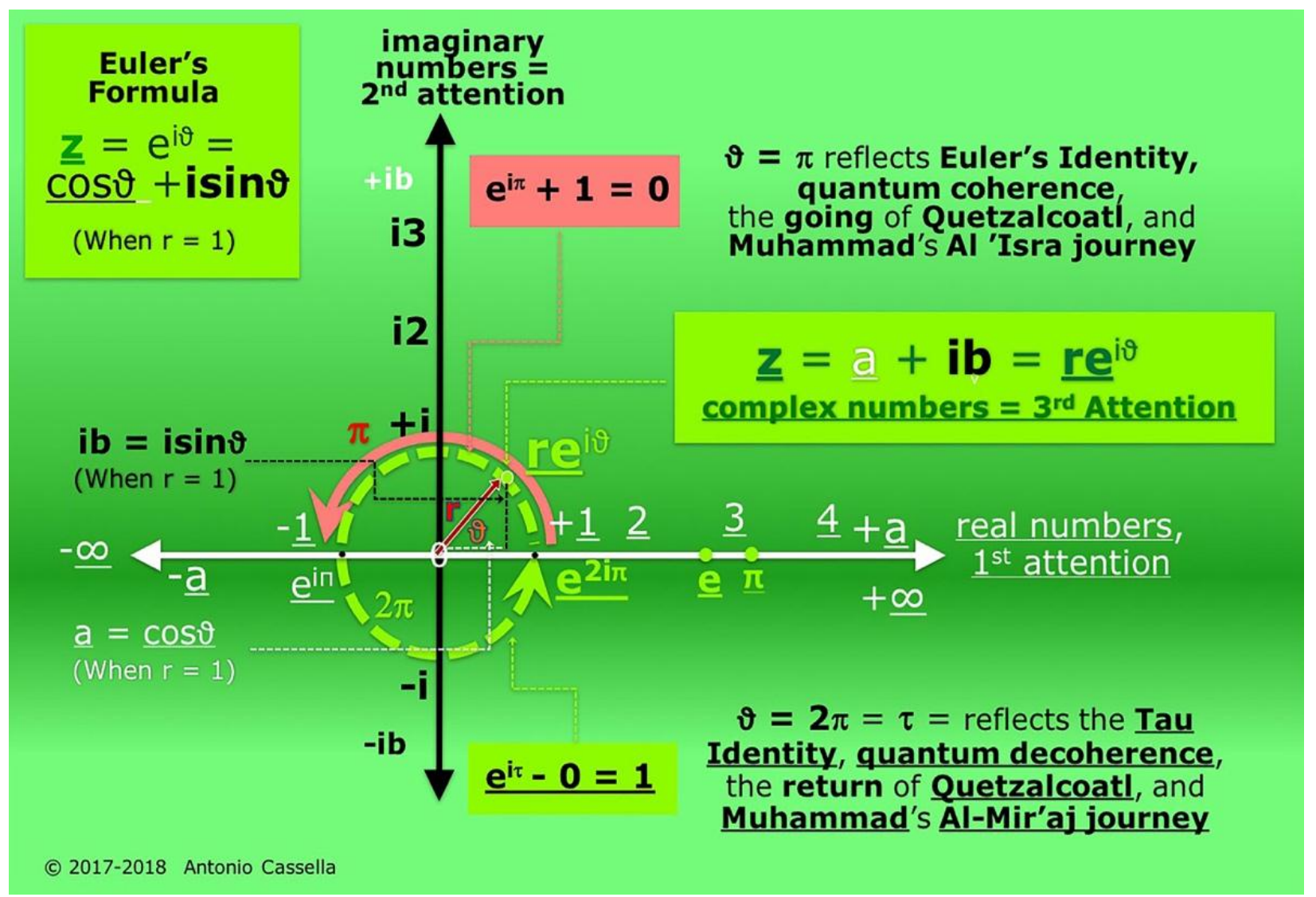

Figure 7. A view of the psychological nature of complex numbers 
It is worth examining the advantages that mathematics derives from using polar coordinates. In polar coordinates, any complex number can be seen as a point in a circumference with a value of $r e^{i \theta}$. In the polar notation just introduced, $r$ represents the radius of the circle centered on the crossing of the horizontal axis with the vertical axis, $e$ is Euler's number, $i$ is the imaginary unit (or the square root of -1 ), and $\theta$ is the angle between the radius and the axis of real numbers.

Continuing with known concepts of mathematics, when $r=1$, the vertical distance between a complex number on the unitary circumference and the horizontal axis becomes both the imaginary part $(i b)$ and the sine of the angle $\theta$. Figure 7 shows also that the associated horizontal distance becomes both the real part ( $\underline{a})$ of a complex number and the cosine of $\theta$.

Replacing the values of $\underline{a}$ and $i b$ in the equivalence $z=\underline{a}+i \boldsymbol{b}=e^{i \theta}$ results in $z=\underline{\cos \theta}+i \sin \theta=e^{i \theta}$, which is called Euler's formula when $r=1$. When $\theta$ becomes Greek Pi in radians, at the left of the center of Figure 7, Euler's formula changes into $e^{i \pi}=-1+0$, which becomes $e^{i \pi}+1=0$, or Euler's Identity.

Beyond Feynman's observation that Euler's Identity is very beautiful, I compare it to quantum coherence and to the going al'Isra journey of Muhammad (at the top of Figure 7). I also need to add that his desire to explore beauty moved Muhammad to continue mounting his winged horse al Burãk (quantum computing) in undertaking his al-Mi'raj returning journey (at the bottom of Figure 7).

\subsection{The Rise of Greek Tau and of an Identity Complementary to and More Beautiful than Euler's}

On the wake of Muhammad's quantum feat, the logos heuristic may enhance our perception of the beauty of Euler's Identity. Notice that Euler's Identity agrees with the phase of quantum coherence that goes from the sanity of a positive real number into the insanity of a negative real number, after crossing the axis of imaginary numbers.

As such, Euler's Identity matches: the infinite speed of quantum coherence in the going journey of Quetzalcoatl; the angels going up the ramp of hyperspace in the dream that Jacob had at Bethel; the ambiguous use of the stone Urim stored in the Ark of the Covenant; the quantum doubts that fill the mind of Arjuna at the beginning of the Bhagavad Gita; the phase of the Ramayana in which the diabolical Ravana takes Sita with him; Muhammad's al'Isra journey to the Farthest Mosque; the tension in the script of a good play; and the Nagual that, according to Don Juan (Castaneda, 1972), allows a Man-of-Knowledge (or a Woman-of-Knowledge) to wake up in a place different from the one in which he or she got asleep; and entanglement in quantum mechanics.

Unlike autistics, nonautistic children at risk for schizophrenia can follow the infinite speed enclosed in quantum coherence and Euler's Identity. However, the inability of adult schizophrenics to return to a renovated reality through quantum decoherence allows us to realize that the alleged beauty of quantum coherence alone may lead us to die in the arms of madness. Still, the rich lives of the painter Vincent van Gogh and of the mathematician John Nash suggest that the edge of schizophrenia hides unknown treasures. As with the going Quetzalcoatl, any sagacious explorer will seek the treasures hidden by nature in the negation of known reality, while trying to avoid a shocking death in a schizophrenic prison.

In the Odyssey, for example, Ulysses asks his companions to tie him to the mast of his ship, so that he would not fall prey to the gracious songs of the mermaids. Muhammad too appreciated the surprising gifts conceded by God to the minds that travel beyond spacetime. Indeed, we know that he leaned on the infinite speed of his al'Isra journey to visit the Patriarch Abraham in the seventh layer of Paradise. After looking at schizophrenic hell (implied by -1 in Figures 1, 2, 3, 5,6 and 7), however, Muhammad did not delay his return to Mecca.

We may assume, then, that the Archangel Gabriel helped him jump from his al'Isra into his al-Mi'raj flight in reaching his Third Attention and returning to the Black Stone in Mecca. Under that assumption, the atoned Haji-pilgrims that renew their cognitive and spiritual stance, after turning seven times around the Black Stone, will replenish their selves before returning to a renewed familiar world.

All pilgrims on Earth may return to a better reality by means of quantum decoherence. We do that when we pass from the angle $\pi$ to the angle $2 \pi$, or to the $\tau$ (Tau) sought by minds who know that the beauty of Euler's Identity, per se, is not good enough!

The insufficiency of Greek Pi is why Jacob dreamt in Bethel of angels that descended a ramp, why Toltec sages envisaged the return of Quetzalcoatl from Venus, why the angel Moroni told Joseph Smith that combining the second attention (represented by the crystal Urim) with the first attention (represented by the crystal Thummim) in the place in which God resides would lead him to a treasured translation of the ancient Book of Mormon; and why the prophet Zechariah implied that we should unite the staff No'am with the staff Hovalim before losing both.

Similarly, Don Genaro (an explorer of the strange ways of quantum neural computing in Carlos Castaneda's books) insinuated to Carlos Castaneda (Castaneda, 1972) that dreaming only with the infinity (the Principle of Ubiquity) of the Nagual of the second attention would preclude his return to his native Ixtlán—a metaphor for the seemingly invariant 
frame of illusory memories that we call home. A few years later (Castaneda, 1991), however, Don Juan (Don Genaro's guide) implied to Carlos Castaneda that the arrival of the Eagle of the Third Attention in the mind of any explorer of the infinity and nothingness inherent in quantum computing would allow him or her to land back into a renewed familiar world.

Don Juan did not hide from Carlos Castaneda the fact that the power of the Nagual is dangerous. In his view, any warrior-explorer who reaches that power, at the end of his or her journey in quantum coherence, may suffocate in the arms of madness. The only alternative open to sensible warriors is to hand out their power to freely decide what to say and what to do to their spontaneous, social, humorous, and humanistic vein. For example, the countless modes of laughing of Don Juan united the quantum talent of his Nagual with the classical respect of his Tonal. Don Juan clearly showed Castaneda that the warrior who learns to laugh at the most embarrassing situations will embrace the Eagle of the Third Attention in returning as a Man-of or as a Woman-of-Knowledge to a better self and to a better other. Quetzalcoatl will do just that in returning to Earth with the secret of the ultimate nature of the Third Attention.

In pursuing the return of Quetzalcoatl on the wake of Muhammad al-Mi'raj flight, my high-school knowledge of algebra leads me to envisioning that if the angle $\pi$ became $2 \pi$ (or $\tau$ ), Euler's Identity would change into $e^{2 i \pi}-1=0$; or $e^{i \tau}-1=0$. Since I do not know if it already has a name, I will give temporarily the name "Tau" to that identity.

Euler's Identity, or $e^{i \pi}+1=0$, and its complement, the "Tau" Identity, or $e^{i \tau}-1=0$, are not the same thing. Autistics cannot fathom the quantum coherence that hides behind Greek Pi in Euler's Identity, whereas unmedicated schizophrenics cannot fathom the quantum decoherence behind Greek Tau, in returning to a renovated shared reality. I hypothesize further that zero is algebraic in Euler's Identity and transcendental in the Tau Identity. Another metaphorical example will reflect the difference between the algebraic zero hidden in the aspect of Quetzalcoatl that might go mad with Euler's Identity and the transcendental zero that adorns the side of Quetzalcoatl that will return to help us all through an understanding of the renewing value of the Tau Identity $\left(e^{i \tau}-1=0\right)$.

\subsection{The Algebraic and Transcendental Facets of Zero}

When the Athenian Xenophon became the main general of the 10000 Greek mercenaries that survived the Battle of Cunaxa in 401 BCE, the Greeks decided to reach and pass the source of the Euphrates River, after crossing the mountains of Armenia, in order to reach the Black Sea (Xenophon, 410 BCE). The Greeks suffered enormously along their voyage in the wings of Euler's Identity. But a day came up in which their wretchedness changed into elation. On that auspicious day, while Xenophon was inspecting the rear guard, he heard an unusual noise that came from a group of hoplites that had reached the top of a mountain.

The general ran immediately toward the noise and the forefront of the 8000 remaining Greeks. When he reached the top of the mountain from which the noise expanded in all directions, he saw that the hoplites of the vanguard embraced each other while they cried "thálatta! thálatta!" ("the sea, the sea"). From the mountain top they had reached, the Greeks could see the Black Sea, which would support their return to Greece, the home in which their journey had begun.

The top of any of the several mountains crossed by the Greeks can be compared to the nothingness of algebraic zero in quantum coherence. But the top of the particular mountain from which they could envisage their return to Greece can be taken as the transcendental zero that precedes quantum decoherence. Indeed, on the transcendental top that Xenophon's hoplites had reached when they cried the word "thálatta," their ambiguous hope to return to a renewed home changed into the certainty of their returning journey; and algebraic zero in Euler's Identity changed into the transcendental zero that revives the "Tau" Identity.

\subsection{The Journey from Algebraic to Transcendental Numbers}

Greek Pi, Greek Tau, and Euler's number are definitely transcendental. The numbers that are not transcendental are algebraic, as are all rational numbers, some irrational numbers (namely, the square root of 2), and even some imaginary numbers - for example, the product of the square root of 2 by the imaginary unit $i$ (Figure 8).

Figure 8 shows an overall view of numbers under the darkness unleashed by quantum coherence and quantum decoherence. Real numbers at the top of the Figure 8, either rational or irrational, are a particular case of complex numbers.

Modern mathematics asserts that numbers can be either algebraic and countable or transcendental and non-countable. As the mathematician Carl Gauss insinuated, the line of real numbers contains niches in which irrationality and infinity may find a home. Such is the case of the simultaneously transcendental and irrational numbers Greek Pi ( $\pi$ ), Greek Tau $(\tau), e, e^{\pi}$, and $e^{\tau}$.

As shown in Figure 8, I associate countable numbers to our autistic facet (1); imaginary countable and non-countable numbers, to the phase of quantum coherence in our second attention and to the al'Isra journey of Muhammad to the 
Farthest Mosque (2); and complex numbers, to Muhammad's al-Mi'raj return (3). As I see it, the complex ways of the Third Attention fill the niches of infinity and nothingness in the line of real numbers, as does the Black Stone in the soul of the atoned Haji pilgrims that visit Mecca.

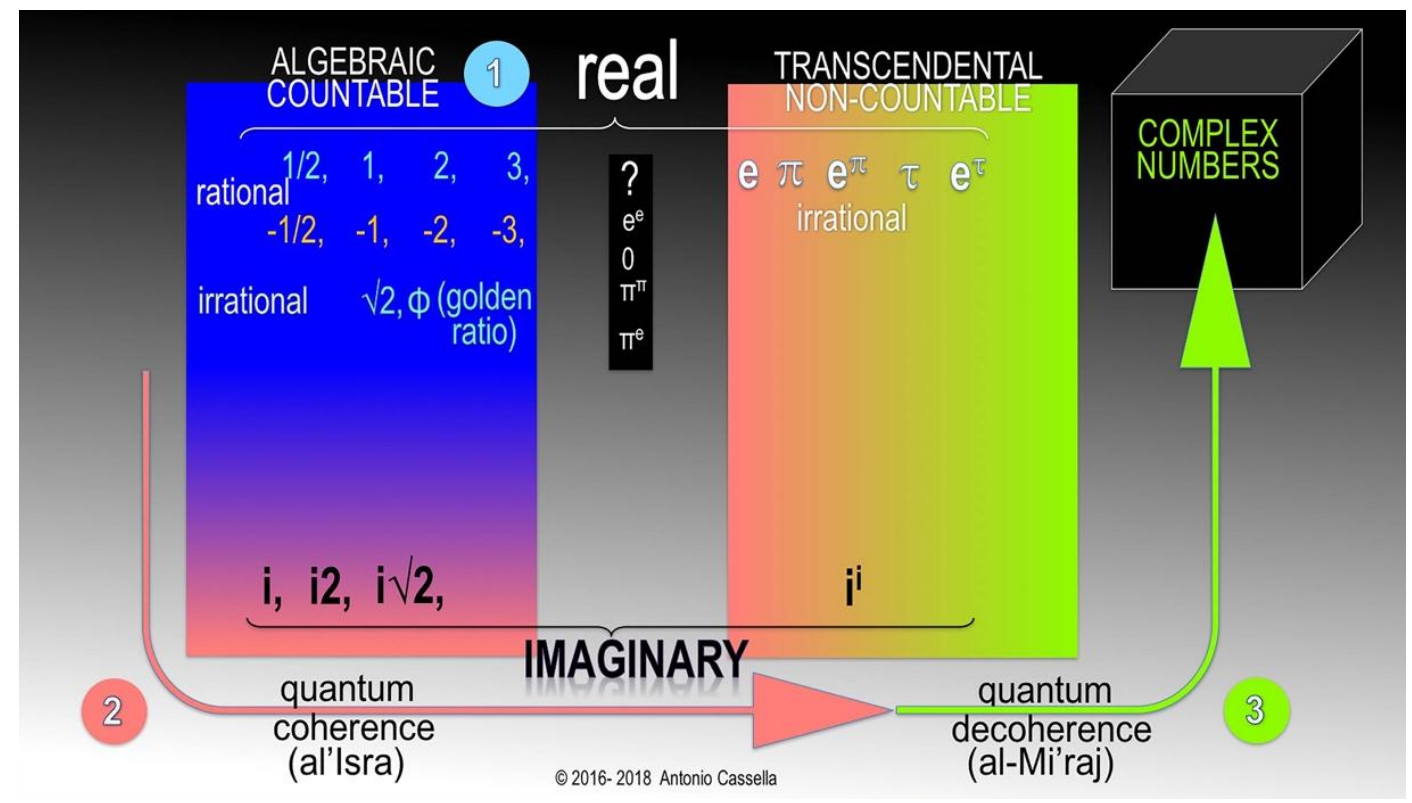

Figure 8. An overall view of the complex relationship between algebraic and transcendental numbers

Greek Pi might be compared to the going journey of Quetzalcoatl, or to a Bodhisattva capable of exploring the madness of a different universe in searching for a new scheme; and Greek Tau can be compared to the return of that Bodhisattva (or Quetzalcoatl) to the sanity of our uni verse, in order to make life better for humans and nonhuman species. Although most drivers love the exploration allowed by four-wheel-drive vehicles, we should not forget that the exploration ascribed to Greek Pi hides the scythe of death in the arms of madness. Unlike autistics, we can explore virgin paths under the spell of Greek Pi and the courage of Quetzalcoatl. However, we should not forget that only Greek Tau and the return of Quetzalcoatl show the glory that renews the self and the other. At this point, another metaphorical example is due.

\subsection{Greek Pi, Greek Tau, and the Death of the Bullfighter Manolete}

Figure 7 and Figure 8 may help explain the unexpected death of Manolete on August 28, 1947. That bullfighter had been wounded the day before in the "Plaza de Toros" ("bull-square") of Linares (Spain). On the day of his last "corrida," Manolete rejected the first bull he was offered, under the belief that its low ferocity would not allow him to surpass the prizes already given to his close competitor, Luis Miguel Dominguín. After his request, he was given a massive and ferocious Miura bull named "Islero."

Manolete danced around Islero waving the red cape that distracted the bull and hid the deadly curvature of his "estoque" sword. His dancing steps around Islero and algebraic zero, between the +1 of sanity and the -1 of insanity (Figures 1,2 , $3,6$, and 7$)$, may be ascribed to the qubit $\mid 1>$ and $\mid 0>$ inherent in quantum coherence.

Manolete had become famous because of his ability to stop dancing within the quantum coherence evoked by Greek Pi, stand still at the -1 of madness, and turn only by 90 degrees when a ferocious bull passed near his body. That fatidic day, however, when Manolete stopped his dancing steps and plunged his estoque in Islero, the band of the Plaza de Toros of Linares stopped playing its pasodoble: One horn of the bull had penetrated the upper part of Manolete's right leg.

Before dying at dawn of the following day by reason of an excessive loss of blood, Manolete was told that Islero had already died under the shadow of that cause. After Manolete died, Miguel Luis Dominguín declared that he had become the best bullfighter of Spain. His statement implied indirectly that, before dying, Manolete made the real best.

The death of Manolete near the semicircle that ends in the angle $\pi$ confirms the dangers that surround raging madness and algebraic zero (the ferociousness of Islero). However, the death of Manolete cannot be associated solely with algebraic zero. Had Manolete survived by accepting a less ferocious bull after the artful display of Dominguín, he would have never seized the glory that will accompany forever his memory in the social mind of Spaniards.

The victories of Manolete before his death, and especially the victory over both his autistic and his schizophrenic self on the day of his death, show that when a hero dies near Greek Pi, on the path of his or her dreams, Greek Tau (or $2 \pi$ ) 
will bring implicitly his return and the return of Quetzalcoatl into a better home for all. Manolete's choice of a combative bull, then, confirms that the quantum embrace of Greek Pi with Greek Tau brings about the true return of Quetzalcoatl.

Similarly: Johanna (van Gogh's wife) leaned on the "Tau" Identity to bring back into the real world the unreal paintings that her husband had found through Euler's Identity, after embracing madness near algebraic zero; and Alicia Nash underwent a similar decoherence journey when she gave up her career in order to anchor the schizophrenic side of the mind of John Nash to a surprising reality in which he was given a Nobel prize. Both women benefited humanity beyond any dream.

\section{Concluding Remarks}

The Spanish phrase, "a toro pasado, todos somos Manolete" ("After the bull is killed, we all become Manolete") may become a metaphor for the fact that each of us can choose the risks associated with Euler's Identity $\left(e^{i \pi}+1=0\right)$ and overcome them by valuing its complement, the identity $e^{i \tau}-1=0$. Valuing the latter "Tau" Identity implies the disposition to risk dying on the way of one's own dreams. All atoned heroes know that Manolete in them and memory in their travel companions will help them return to a better reality: One that sublimates global warming into wisdom.

This paper is not about global warming and terrorism. Still, one cannot quash the thought that if global civilization ends abruptly and shamefully at the turn of the $21^{\text {st }}$ century, there would be few people left to remember the glorious return of a dead Manolete, the glorious return to Mount Olympus of a lively Xenophon, and the glorious return of ancient social values. I am pointing at the values hidden in our Sacred Texts, in masterpieces of the arts, in our victories at the edge of madness, and in the true beauty of Euler's Identity and of the "Tau" Identity.

As with most people, I will never master the complex knowledge stored in pure mathematics. And yet the psychological view of numbers shown in this article suggests that all branches of mathematics reflect the three modes of attention that guide the human mind. Additional research can falsify that hypothesis.

A psychological view of mathematics may help us conclude that we can avoid the end of time and the premature death of our great grandchildren at the turn of the $21^{\text {st }}$ century. If we use the power of our Third Attention to understand better past climatic havocs and to imagine a better atmosphere and a better social world for the self and the other, we will overcome any challenge under the sun. Our desire to conjure the affection of our great grandchildren will help us win over the fear of failing miserably. As with Manolete, any hero that dies near algebraic zero on the path of his or her dreams, will nonetheless succeed on the path that marks the beginning of his or her Third Attention near transcendental zero.

For example, if we believe the research undertaken by Milutin Milankovitch in the 1920s (Milankovitch, 1998), the next 7000 years will bring about a new cycle of moderate global cooling (Hays, Imbrie, and Shackleton, 1976). If we do not increase by two degrees Celsius the temperature of the lower atmosphere during the $21^{\text {st }}$ century, nature will lower it by two degrees.

Together, the work of Milankovitch and the hypothesis launched here that numbers follow the distributed organization of the mind and nature into three domains of attention/intention suggest that we can stop anthropic global warming and replace it with natural global cooling. In the same way, we can overcome the ills attached to terrorism by absorbing the esoteric teachings hidden in our Sacred Texts and by re-educating our minds.

If we restrain our indifference, ignorance, blindness, arrogance, ideology, denial, madness, narcissism, ambition, and egoism, we will undertake bravely the journey of quantum decoherence, as did our ancestors in the Stone Age, Xenophon, and Manolete.

In reeducating our minds and the minds or our children, we will understand how the autistic mind works, how the schizophrenic mind works, and how the social mind works. Those three pieces of knowledge will help us reach the simultaneous differentiation and unification of all Sacred Texts, all masterpieces of the arts, all sciences and all branches of mathematics. Although the Heraclitean "logos" seems at odds with the Pythagorean "number," this article stresses that the propositions "all is logos" and "all is number" are equivalent.

\section{Brief Biography of Antonio Cassella}

EdD: Teaching and Research (UNESR: Universidad Nacional Experimental Simón Rodríguez, Caracas);

MA: Psychology (Harvard University, Cambridge [MA]);

BSc: Petroleum Engineering (LUZ: La Universidad del Zulia, Maracaibo).

The web page and the writings of the author can be reached by placing the words "Antonio Cassella" in the space set aside for authors at Amazon Kindle or Amazon Prime. Readers interested in deepening the implications of the logos psychological heuristic may contact Antonio Cassella at researchautism.1@gmail.com. 
Antonio Cassella was born in Ethiopia in 1940. He enjoyed his high-school education in Italy and in Venezuela. He obtained a BSc in Petroleum Engineering from LUZ in Maracaibo in 1965. In the next 17 years Antonio developed new oil fields in the tidal bay of Maracaibo with Creole Petroleum Corporation (a subsidiary of Esso/ExxonMobil), Lagoven SA, and PDVSA (Petróleos de Venezuela). The need to remove hydrogen sulfide from associated gas led him to working in 1976 for EPRCO (Exxon Production Research) in Houston.

Between 1983 and 1993, Cassella worked in Strategic Planning of PDVSA in Caracas. As a visiting scientist at MIT-CEEPR (Massachusetts Institute of Technology-Center for Energy and Environmental Policy Research, Cambridge (MA)), between 1994 and 1997 his diurnal research led to establishing two scenarios of the global growth of population, energy, and the economy until 2060. In June 1997, his nocturnal research on the psychological roots of autism and creative intelligence brought him a Master's degree in Psychology and the Award for Outstanding ALM Thesis in the Area of Natural and Human Sciences from Harvard University.

In 2001 Antonio Cassella received in Caracas a Doctoral degree in Research and Teaching in Sciences of Education from UNESR. His writings in Italian, Spanish, and English (only at Amazon Kindle and Prime) show that combining the local certainty sought by our autistic self with the nonlocal doubt sought by our artistic self may help modern society to defuse fanaticism and global warming, while regenerating the Commons of the Earth-among them, the atmosphere and the cycle of water.

Since 2014, Antonio directs the research effort of Research Autism. Research Autism has published a series of four documentary-films on the logos heuristic in English, Spanish, and Italian.

The first link of the English series is https://youtu.be/htt6xh2i5B8;

the first link of the Spanish series is https://youtu.be/wNh0CgZtJMU;

and the first link of the Italian series is https://youtu.be/hbcW4Z12Vu8.

\section{References}

Baron-Cohen, S. (1995). Mindblindness. Cambridge, MA: MIT Press.

Baron-Cohen, S., Leslie, A. M., \& Frith, U. (1985). Does the autistic child have a 'theory of mind?' Cognition, 21, 37-46. https://doi.org/10.1016/0010-0277(85)90022-8

Baron-Cohen, S., Tager-Flusberg, H., \& Cohen, D. J. (1993). Understanding other minds: Perspectives from autism. Oxford: Oxford University Press.

Caramazza, A. (1994). Parallels and divergences in the acquisition and dissolution of language. Philosophical Transactions of the Royal Society of London, Series B. 346, 121-127. https://doi.org/10.1098/rstb.1994.0136

Cappelletti, Ángel J. (1972). Los fragmentos de Heráclito. Caracas: Tiempo Nuevo.

Cassella, A. (1997). Self-other differentiation and self-other integration from the perspectives of language development and autism. (Unpublished master's thesis). Harvard University, Cambridge, USA.

Cassella, A. (2000). Fundamentos cognitivos y semióticos de la creatividad: Aportes del autismo. (Tesis doctoral con mención publicación). Universidad Nacional Experimental Simón Rodríguez (UNESR), Caracas, Venezuela.

Cassella, A. (2002a). El desarrollo de la inteligencia social: Aportes del autismo. Maracaibo, Venezuela: Ediluz.

Cassella, A. (2002b). The Flameless Fire: From autism to creative intelligence. Quincy (MA): Logosresearch. (Re-edited in a digital format in 2017 by Research Autism through Amazon Kindle).

Cassella, A. (2008). Readjusting what we know with what we imagine. In R. Allen (Ed.) Human ecology economics: A frameworkfor global sustainability (pp. 230-257). London: Routledge.

Cassella, A. (2011, June). Autism and the interplay of deterministic and quantum information processing in the act of creation. Neuroquantology, 9(02), 271-287.

Cassella, A. (2013). Neurobiological correlates of classical and quantum neural computing from the perspective of autism. In V. B. Patel, V. B. Preedy, \& C. R. Martin (Eds.), The comprehensive guide to autism (pp. 865-890). London: Springer. https://doi.org/10.14704/nq.2013.11.2.623

Cassella, A. (2016). The psychological roots of creativity in messages left by Leonardo da Vinci, Giorgio Vasari, and a Neanderthal troglodyte. Journal of Arts and Humanities, 5(8), 12-28.

Cassella, A. (2017a). Thus returned Quetzalcoatl: An interview with Antonio Cassella concerning the Dance of locality and nonlocality. Melbourne (FL): Research Autism. (Series of 3 volumes in English, Spanish, and Italian).

Cassella A. (2017b). An unlawful look at an extraordinary theory-of-everything: Answers to fifteen questions concerning the dance of locality with nonlocality. Melbourne (Florida): Research Autism. (Edited in English, Spanish, and 
Italian).

Cassella, A. (June 2017c). Re-directing climate change and terrorism by allying classical with quantum neural computing. International Journal of Social Science Studies, 5(6), 94-115. https://doi.org/10.11114/ijsss.v5i6.2439

Cassella, A. (2017d, documentary-film). An unlawful look at an extraordinary theory-of-everything: Answers to 15 questions concerning the dance of locality with nonlocality. Melbourne (FL): Research Autism (YouTube).

Cassella, A. (2017e, documental). Una ojeada ilícita a una extraordinaria teoría-del-todo: Respuestas a quince preguntas sobre una extraordinaria teoría-del-todo. Melbourne (FL): Research Autism (YouTube).

Cassella, A. (2017f, documentario). Un'occhiata illecita a una straordinaria teoria-del-tutto; Risposte a quindici domande sulla danza della località con la non località. Melbourne (FL): Research Autism (Youtube).

Cassella, A. (October 2017g). Freeing Leonardo da Vinci's Fight for the Standard in the Hall of the Five Hundred at Florence's Palazzo Vecchio. International Journal of Social Science Studies, 5(10), 01-16.

Castaneda, C. (1972). Journey to Ixtlán: The lessons of Don Juan. New York, NY: Simon and Schuster.

Castaneda, C. (1991). The Eagle’'s gift. New York, NY: Simon and Schuster.

Copplestone, F. C. A. (1962a). A history of philosophy: Greece and Rome. New York: Image Books.

Copplestone, F. C. (1962b). A history of philosophy: Medieval Philosophy. New York: Image Books.

Courchesne, E., To wnsend, J. P., Akshomoof, N. A., Yeung-Courchesne, R., Press, J. A., Murakami, J. W., ... Schreibman, L. (1994). "A new finding: Impairment in shifting attention in autistic and cerebellar patients." In Atypical cognitive deficits in developmental disorders: Implications for brain function, edited by Sarah Broman and Jordan Grafman, 101-137. Hillsdale, N.J: Erlbaum.

Greenblatt, S. (2012). Il Manoscritto: Come la storia di un libro perduto cambiò la storia della cultura europea . Milano: Rizzoli.

Hays, H. D., Imbrie, J., \& Shackleton, N. J. (1976). Variations in the Earth's orbit: Pacemaker of the Ice Ages. Science, 194(4270), 1121-1132. https://doi.org/10.1126/science.194.4270.1121.

Johnson, M. H. (1994). Visual attention and the control of eye movement in early infancy. In C. Umiltà \& M. Moscovitch (Eds.) Attention and performance XV: Conscious and nonconscious information processing (pp. 291-310). Cambridge (MA): The MIT Press.

Katznelson, M. (1991). La Biblia: hebreo-español. Tel Aviv: Sinai. (See Zechariah, 11:07; 11:10; 11:14; 13:07; 13:08).

Köestler, A. (1964). The act of creation. Hutchinson: London.

Landry, R., \& Bryson, S. (June 2004). Impaired disengagement of attention in young children with autism. Journal of Child Psychology and Psychiatry, 45(6), 1115-1122. https://doi.org/10.1111/j.1469-7610.2004.00304.

Milankovitch, M. (1998). Canon of insolation and the ice-age problem. Belgrade: Textbook Publishing Company.

Padrón, G. J. (1996). Análisis del discurso e investigación social. Caracas: UNESR.

Povinelli, D. J, Landau, K. R, \& Perilloux, H. K. (1996). Self-recognition in young children using delayed versus live feedback: Evidence of a developmental asynchrony. Child Development, 67, 1540-1554. https://doi.org/10.2307/1131717.

Ward, P. D. (October 2006). Impact from the Deep. Scientific American, 295, 64-71. https://doi.org/10.1038/scientificamerican1006-64

Xenophon. (410 BCE). Anabasis: The march up country. (Translated by W.H.D. Rouse in 1958). Ann Harbor (Michigan): The University of Michigan Press.

Zaitchik, D. (1990). When representations conflict with reality: The preschooler's problem with false beliefs and 'false' photographs. Cognition, 35, 41-68. https://doi.org/10.1016/0010-0277(90)90036-J

\section{Copyrights}

Copyright for this article is retained by the author(s), with first publication rights granted to the journal.

This is an open-access article distributed under the terms and conditions of the Creative Commons Attribution license which permits unrestricted use, distribution, and reproduction in any medium, provided the original work is properly cited. 